\title{
Tribocorrosion Behavior of Inconel 718 Fabricated by Laser Powder Bed Fusion-Based Additive Manufacturing
}

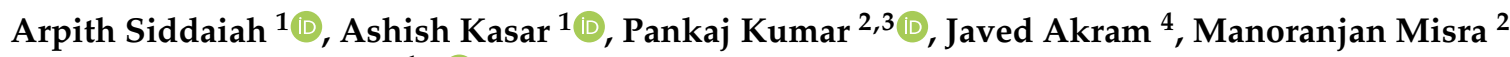 \\ and Pradeep L. Menezes ${ }^{1, *(\mathbb{D})}$ \\ 1 Department of Mechanical Engineering, University of Nevada, Reno, NV 89557, USA; \\ asiddaiah@nevada.unr.edu (A.S.); akasar@nevada.unr.edu (A.K.) \\ 2 Department of Chemical and Materials Engineering, University of Nevada, Reno, NV 89557, USA; \\ pankaj@unm.edu (P.K.); misra@unr.edu (M.M.) \\ 3 Department of Mechanical Engineering, University of New Mexico, Albuquerque, NM 87131, USA \\ 4 Ansys, 1794 Olympic Parkway, Site\#110, Park City, UT 84098, USA; jaavedakram@gmail.com \\ * Correspondence: pmenezes@unr.edu; Tel.: +1-(775)-682-7413
}

Citation: Siddaiah, A.; Kasar, A.; Kumar, P.; Akram, J.; Misra, M.; Menezes, P.L. Tribocorrosion Behavior of Inconel 718 Fabricated by Laser Powder Bed Fusion-Based Additive Manufacturing. Coatings 2021, 11, 195. https://doi.org/ 10.3390/coatings11020195

Academic Editor: Kevin Plucknett Received: 21 December 2020

Accepted: 5 February 2021

Published: 8 February 2021

Publisher's Note: MDPI stays neutral with regard to jurisdictional claims in published maps and institutional affiliations.

Copyright: (c) 2021 by the authors. Licensee MDPI, Basel, Switzerland. This article is an open access article distributed under the terms and conditions of the Creative Commons Attribution (CC BY) license (https:// creativecommons.org/licenses/by/ $4.0 /)$.

\begin{abstract}
Additive manufacturing (AM) by laser powder bed fusion (LPBF) has gained significant research attention to fabricate complex 3D Inconel alloy components for jet engines. The strategic advantages of LPBF-based AM to fabricate jet components for aerospace applications are well reported. The jet components are exposed to a high degree of vibration during the jet operation in a variable aqueous environment. The combined vibration and the aqueous environment create a tribological condition that can accelerate the failure mechanism. Therefore, it is critical to understand the tribocorrosion behavior of the Inconel alloy. In the present work, tribocorrosion behavior of the LPBF fabricated standalone coating of Inconel 718 in the $3.5 \% \mathrm{NaCl}$ aqueous solution is presented. The LPBF fabricated samples are analyzed to determine the impact of porosity, generated as a result of LPBF, on the triobocorrosion behavior of AM Inconel 718. The study includes potentiodynamic tests, cathodic polarization, along with OCP measurements. The corrosive environment is found to increase the wear by $29.24 \%$ and $49.5 \%$ without the initiation of corrosion in the case of AM and wrought Inconel 718, respectively. A corrosion accelerated wear form of tribocorrosion is observed for Inconel 718. Additionally, the corrosive environment has a significant effect on wear even when the Inconel 718 surface is in equilibrium potential with the corrosive environment and no corrosion potential scan is applied. This study provides an insight into a critical aspect of the AM Inconel components.
\end{abstract}

Keywords: additive manufacturing; Inconel 718; friction; wear; tribocorrosion; corrosion

\section{Introduction}

Inconel 718 is a super-alloy. Due to its excellent high-temperature performance, it is widely used in aircraft turbojet engines as discs, blades, and casing for high-pressure sections of aircraft engine components. It also finds application in rocket engines and cryogenic environments due to its good toughness at low temperatures, which protects the components from brittle fracture. Due to excellent mechanical properties and wear resistance, the Inconel 718 is favorable for aerospace, marine and chemical industries. However, the higher shear strength and low material removal rate of Inconel 718 create difficulty in machining, especially for complex parts where tight dimensional accuracy is required [1-3]. Additive manufacturing (AM) provides an excellent opportunity to overcome the difficulty of conventional machining to develop a complex structure of Inconel $718[4,5]$.

Among the different methods of AM techniques, laser powder bed fusion (LPBF) has gained tremendous attention due to its capability to fabricate a fully dense component [6,7]. LPBF is also referred as direct laser sintering or selective laser melting. LPBF technique involves layer-by-layer formation where a layer of powder is applied to the 
platform/substrate and subsequently melted using laser. The melting of the powders causes bonding between powders and forms the first layer. Similarly, successive layers of powders are formed to fabricate the coating/parts. LPBF technique has been used to fabricate different standalone coatings (ref.) and 3D components (ref.) of various materials such as Ti6Al4V coating [8], tantalum coating [9], Ti-SiC coating [10], 316L stainless steel [11], and Inconel 718 [12] etc.

LPBF has enabled customization of Inconel 718 components with easy production of complex shapes and geometries. During its operation, especially in aircraft and jet applications, the material may come in contact with various extreme and aqueous environments in addition to tribo-contacts with other materials [13]. These conditions can cause early failure or reduced performance of AM Inconel 718 components if the AM design or fabrication process has any flaws. It is also well known that the Inconel 718 provides excellent corrosion resistance. It has been shown that the AM Inconel 718 can maintain pitting corrosion resistance even after low-temperature solution treatments, while high-temperature solution treatments can cause some weakening of the pitting corrosion resistance [13-15]. Additionally, the electrochemical polishing process can significantly improve pitting corrosion resistance. Build direction using LPBF has also shown a significant influence on microstructure and corrosion performance of Inconel 718. The corrosion resistance of the AM Inconel 718 samples increases with the increasing incline angle of LPBF process, and this can be rationalized by considering changes to the grain boundary area [16]. To make the AM Inconel 718 tribo-contact interfaces functionally resistant in extreme environmental conditions, it is necessary to investigate the wear along with the electrochemical behavior of these alloys. Hence, understanding the tribological and tribocorrosion behavior of functionally processed Inconel 718 materials are of practical and theoretical importance.

\section{Materials and Methods}

\subsection{Materials and Electrolyte}

In this investigation, 3D-printed Inconel 718 samples of size $10 \times 10 \times 5 \mathrm{~mm}^{3}$ using the LPBF process were manufactured using SLM ${ }^{\mathrm{R}} 500$ machine (SLM Solutions, Wixom, MI, USA) of maximum power $400 \mathrm{~W}$. The deposition parameters for the sample preparation were: Laser power: $165 \mathrm{~W}$, scan speed: $800 \mathrm{~mm} / \mathrm{s}$, and layer thickness: $0.4 \mathrm{~mm}$. Detailed manufacturing details are given elsewhere [7]. The porosity of $<1 \%$ in the LPBF-processed sample has been observed. The microstructure of the as-fabricated cube sample showed large and interconnected directional columnar grains with random columnar grain as discussed in detail in [7]. A wrought Inconel 718 (purchased from McMaster Carr, Elmhurst, IL, USA) has been used as a control material for comparison of the properties being investigated. The chemical composition of both wrought and as LPBF samples qualifies as ASTM B637 for Inconel 718 alloy [17]. The hardness measurement was carried out using a nano-indenter (T1950 Triboindenter, Hysitron, Minneapolis, MN, USA) equipped with a Berkovich indenter. The nanoindentations were performed at different locations using a maximum force of $5 \mathrm{mN}$. The minimum distance between two indentations was $100 \mu \mathrm{m}$. The hardness value of AM Inconel is $5.36 \pm 0.30 \mathrm{GPa}$, which is slightly higher than the hardness value of Wrought Inconel (4.93 $\pm 0.27 \mathrm{GPa})$.

The tribocorrosion studies were performed on as LPBF and as purchased wrought samples without any further heat treatment. For this study, square plate samples of Inconel 718 (both the LPBF and wrought) with a 1-inch width and 0.5-inch thickness were used to evaluate its tribocorrosion behavior. The surface of the samples was polished using SiC sandpapers with grit sizes starting from 320 ( 46 $\mu \mathrm{m}$ abrasive particles) up to $1200(\sim 15 \mu \mathrm{m}$ abrasive particles), followed by fine polishing using three-micron diamond suspension until a surface roughness conditions of $R_{a}=0.1 \mu \mathrm{m}$ was achieved. The counter material for the tribocorrosion testing was a non-conductive ceramic material, alumina ball of $6.35 \mathrm{~mm}$ diameter. The present tribocorrosion study simulates a corrosive lubricated environment according to ASTM B895-99 [18], where 3.5\% $\mathrm{NaCl}$ solution is used as the electrolyte/lubricant. The test parameters in the present study concentrated on analyzing 
the tribocorrosion behavior in laboratory conditions. The real applications of AM Inconel 718 , such as those in aircrafts may have much more complex boundary conditions, which will include, but may not be limited to, fretting and other vibrations, reciprocating sliding, and other such degradation effects.

\subsection{Open Circuit Potential (OCP) Measurements}

The OCP measurements were carried out on wrought and AM Inconel 718 surfaces to understand and compare their open circuit kinetics in 3.5\% NaCl. The OCP, also known as the corrosion potential is a mixed potential that depends on the rate of the anodic as well as the cathodic reactions. If the corrosion cell involves one dissolution reaction and one cathodic reaction, the corrosion potential will be between the reversible potentials of the two half-reactions. Understanding this evolution of OCP will provide an insight into the kinetics of corrosion without wear. The experiments were conducted using threeelectrode configuration, which consisted of Inconel 718 surface as the working electrode, standard calomel electrode (SCE) as the reference electrode, and 99\% pure graphite as the counter electrode. Figure 1 schematically illustrates the tribocorrosion test setup used for the experiments. The OCP was measured using a Gamry reference 3000 potentiostat. All potential in the present study is reported with reference to SCE, which has a potential of $0.250 \mathrm{~V}$ vs. SHE (standard hydrogen electrode) at $25^{\circ} \mathrm{C}$. A working electrode area of $2.5 \mathrm{~cm}^{2}$ was exposed to the electrolyte. Each test was carried out three times to ensure repeatability of results.

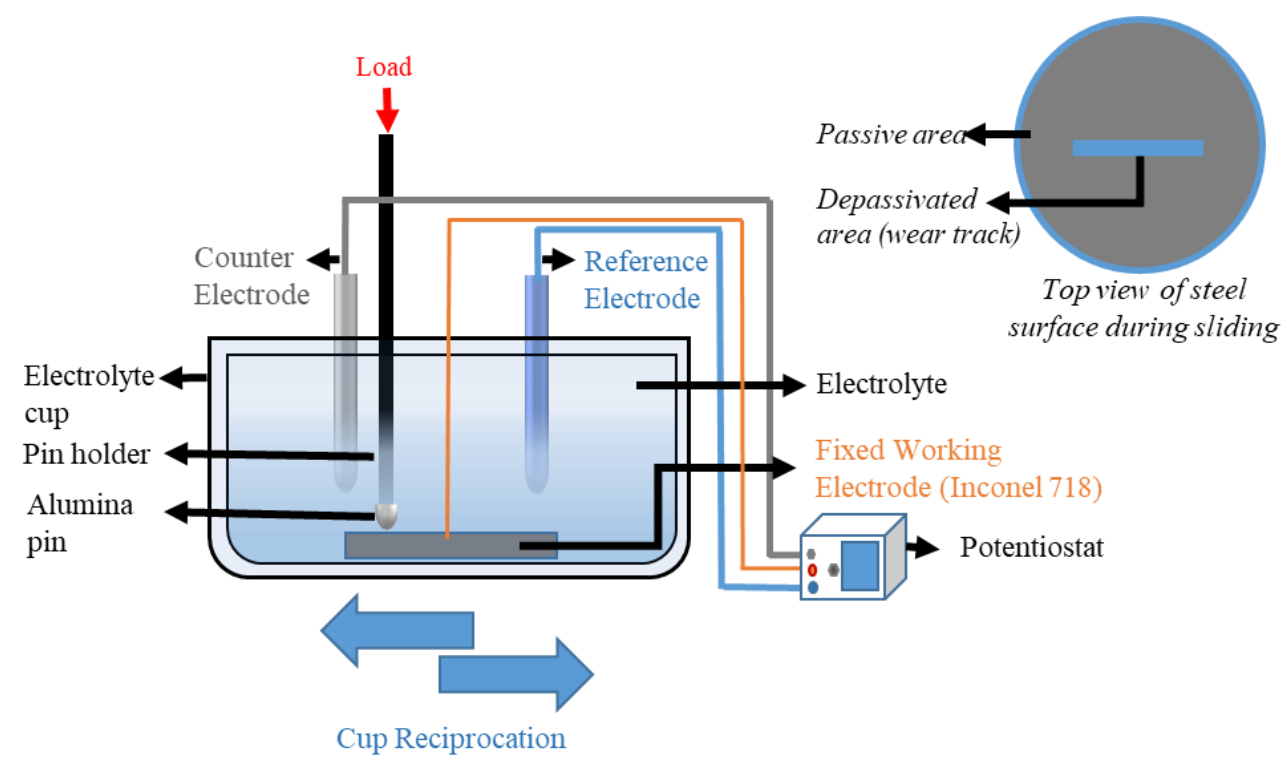

Figure 1. Tribocorrosion test setup and view of the Inconel 718 sample/working electrode.

\subsection{Tribocorrosion Tests}

The synergistic effect between wear and corrosion $(S)$ affects the total material loss rate $(T)$ as

$$
T=W_{o}+C_{o}+S
$$

where $W_{o}$ is the wear component in the absence of corrosion and $C_{o}$ is the corrosion component in the absence of wear. The synergistic component $S$ can be written as

$$
S=\Delta W_{c}+\Delta C_{w}
$$

where $\Delta W_{c}$ is the change in wear rate due to corrosion, and $\Delta C_{w}$ is the change in corrosion rate due to wear. The total wear component is $W_{o}+\Delta W_{c}$, and the total corrosion component is $C_{o}+\Delta C_{w}$. These components in a tribocorrosive system will be measured using a 
combination tribological and electrochemical experiments. The corrosion rate of a material can be obtained using Faraday's law:

$$
V_{c h}=Q M / n F \rho
$$

where $V_{c h}$ is the volume of metal transformed by anodic oxidation, $Q=\int I d t$ is the electric charge passed over the time of the experiment, $M$ is the atomic mass of the metal, $n$ is the charge number for the oxidation reaction, $\mathrm{F}$ is the Faraday constant, and $\rho$ is the density of the metal. Whereas the wear components will be quantified using the Archard's law [19], the relationship between the hardness of the wear volume can be described as:

$$
V / L=k N / H
$$

where $V$ is the volume of wear, $L$ is the sliding distance, $N$ is the normal load, $H$ is the hardness of the softer one in the two contacting materials, and $k$ is the wear coefficient, which is valid to both the adhesive and abrasive wears.

Figure 1 schematically illustrates the tribocorrosion test setup used for the experiments. To isolate wear-corrosion synergism in a standard seawater condition of $3.5 \% \mathrm{wt} \mathrm{NaCl}$, the following series of experiments were performed as per the ASTM G119 [20] for wrought and AM Inconel 718 disks with surface roughness conditions of $R_{a}=0.1 \mu \mathrm{m}$. The counter/ball material used will be alumina of $6.35 \mathrm{~mm}$ diameter.

(1) First, the experiment will be performed using the tribocorrosion monitoring test setup (Figure 1) developed in-house [21]. The setup consists of a pin-on-disk setup, and an electrochemical cell with three-electrode configuration. The total material wear rate $(T)$ of the disk was be measured while monitoring the equilibrium potential during sliding against alumina ball.

(2) Second, the rate of degradation of the disk was determined by measuring corrosion rate in the absence of wear $\left(C_{0}\right)$. The same setup (Figure 1 ) was used without sliding to measure the corrosion rate without wear. The corrosion rate was calculated by a series of electrochemical measurements involving, (i) measuring the equilibrium potential of the disk material, (ii) polarization resistance measurements, (iii) measuring the equilibrium potential of the disk material, and (iv) potentiodynamic polarization tests. The electrochemical corrosion current density was calculated using the results from these tests, and the $C_{o}$ will be obtained by applying Faraday's law (Equation (3)).

(3) Third, the rate of disk degradation in the absence of corrosion $\left(W_{o}\right)$ was determined. The working electrode on the test setup was polarized cathodic with respect to corrosion potential $\left(E_{c o r r}\right)$ to suppress corrosion, and the wear data was collected. The rate of material loss on the disk at the end of the experiment was calculated in Equation (4). This rate of material loss will provide the $W_{o}$.

(4) Fourth, the total corrosion component $\left(C_{w}\right)$ was estimated. Experiments were performed using the test set-up (Figure 1). This stage involved a wear test in addition to the electrochemical experiments from the second stage. The electrochemical corrosion current density as influenced by the wear was calculated using the results from these tests. The $C_{w}$ was then obtained by applying Faraday's law (Equation (3)).

\section{Results and Discussion}

In the present study, $2025.8 \mathrm{~mm}^{2}$ surface area of Inconel 718 was in contact with the electrolyte throughout the tribocorrosion testing. Within this area of contact, the cyclic $10 \mathrm{~mm}$ reciprocating sliding of alumina ball on Inconel 718 surface was the depassivated area (anode), and the remaining unworn surface was the passive area (cathode), thus completing the galvanic couple. The tribocorrosion test was conducted at $\pm 5 \mathrm{~mm} /$ stroke sliding cycle for $60 \mathrm{~min}$; the sliding speed was $0.01 \mathrm{~mm} / \mathrm{s}$ at a normal load of $50 \mathrm{~N}$. The tests were conducted at laboratory conditions of $24^{\circ} \mathrm{C}$ lab temperature and $20 \%$ relative humidity. During the reciprocating tests, potential and current values were recorded on the potentiostat while the wear and friction force was recorded on the tribometer, 
in-situ. A summary of the observed and calculated (using Equations (1)-(4)) results are shown in Table 1, and their implications are discussed in the following sections. A strong synergistic effect was observed on the Inconel Wrought sample with a synergistic factor of 124.93. It is significantly higher compared to that of the Inconel AM sample. By resolving the synergistic effect into wear and corrosion, the component shows a strong effect of corrosion on wear for Inconel wrought. The higher value of $\Delta W_{c}$ in the case of Inconel AM suggests that mechanical wear is drastically influenced by corrosion. Whereas the effect of wear on corrosion is negative that is possibly due to corrosion protection by wear debris. These synergistic terms are discussed in terms of wear volume and corrosion rate in the next subsection.

Table 1. Material loss rate for Inconel AM and Wrought sample during tribocorrosion.

\begin{tabular}{cccccccc}
\hline \multirow{2}{*}{ Sample } & $\boldsymbol{7}$ & $\boldsymbol{W}_{\boldsymbol{o}}$ & $\boldsymbol{C}_{\boldsymbol{o}}$ & $\boldsymbol{C}_{\boldsymbol{w}}$ & $\boldsymbol{S}$ & $\boldsymbol{\Delta} \boldsymbol{C}_{\boldsymbol{w}}$ & $\boldsymbol{\Delta} \boldsymbol{W}_{\boldsymbol{c}}$ \\
\hline Inconel AM & 107.05 & 106.26 & 0.08 & 0.06 & 0.07 & -0.02 & 0.72 \\
Inconel Wrought & 225.40 & 100.40 & 0.07 & 0.06 & 124.93 & -0.01 & 124.94 \\
\hline
\end{tabular}

\subsection{Wear Volume during Tribocorrosion}

The wear behavior was measured for wrought and AM Inconel 718 during the $\mathrm{OCP}$, potentiodynamic, and cathodic polarization tests. The wear volumes with respective wear track profile results for the wrought sample are presented in Figure 2 and for the AM sample are presented in Figure 3. The wear tracks were profiled and analyzed using a 3D optical profilometer. The 3D profiles were used to accurately extract the wear volume under each test condition and were compared. It can be observed in Figure 2 that the wrought Inconel 718 undergoes wear of $2.57 \mathrm{~mm}^{3}$ under the influence of corrosion and wear during the potentiodynamic test. The wear under OCP conditions in the sample is in equilibrium potential with the corrosive environment and is found to be $2.28 \mathrm{~mm}^{3}$. Under cathodic polarization conditions, the effects of corrosion have been electrochemically removed to isolate the wear under the given corrosive environment; the wear is found to be $1.15 \mathrm{~mm}^{3}$.

(a)

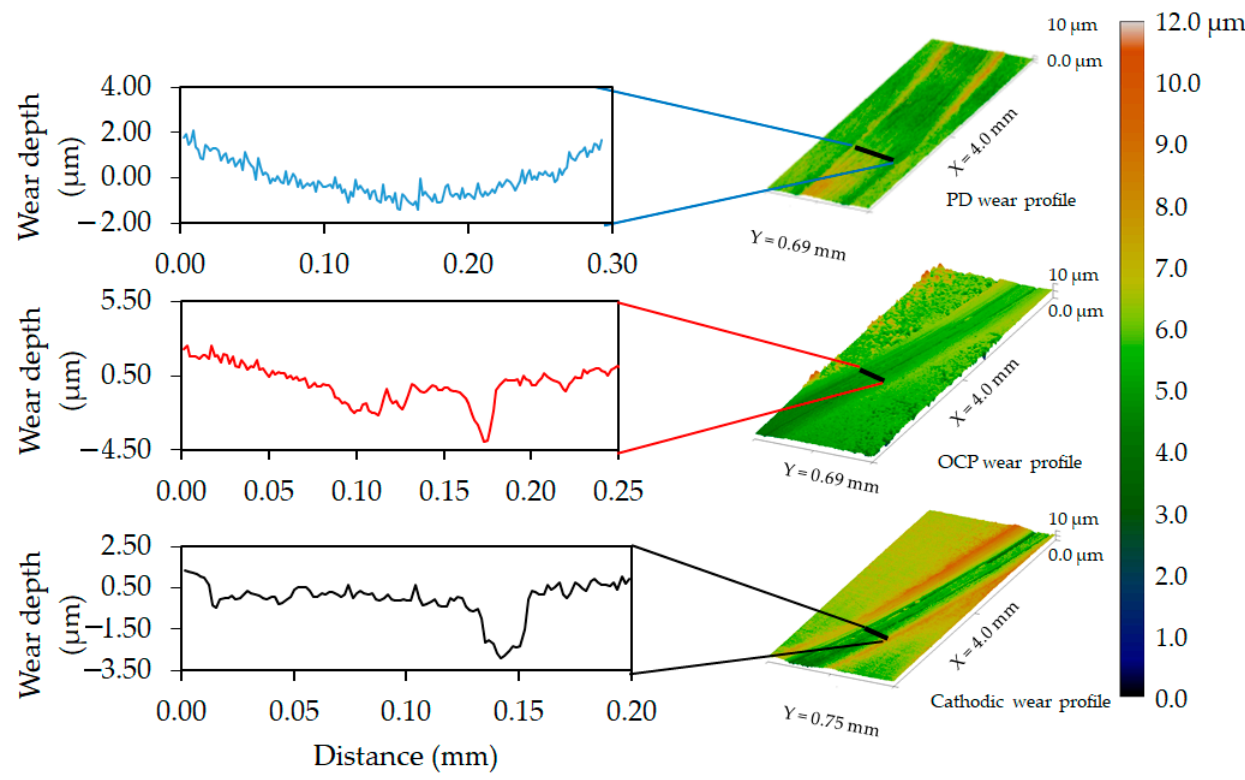

Figure 2. Wear on wrought Inconel 718 after (a) potentiodynamic test, (b) OCP condition, and (c) cathodic polarization test shown alongside a common color scale bar. 
(a)

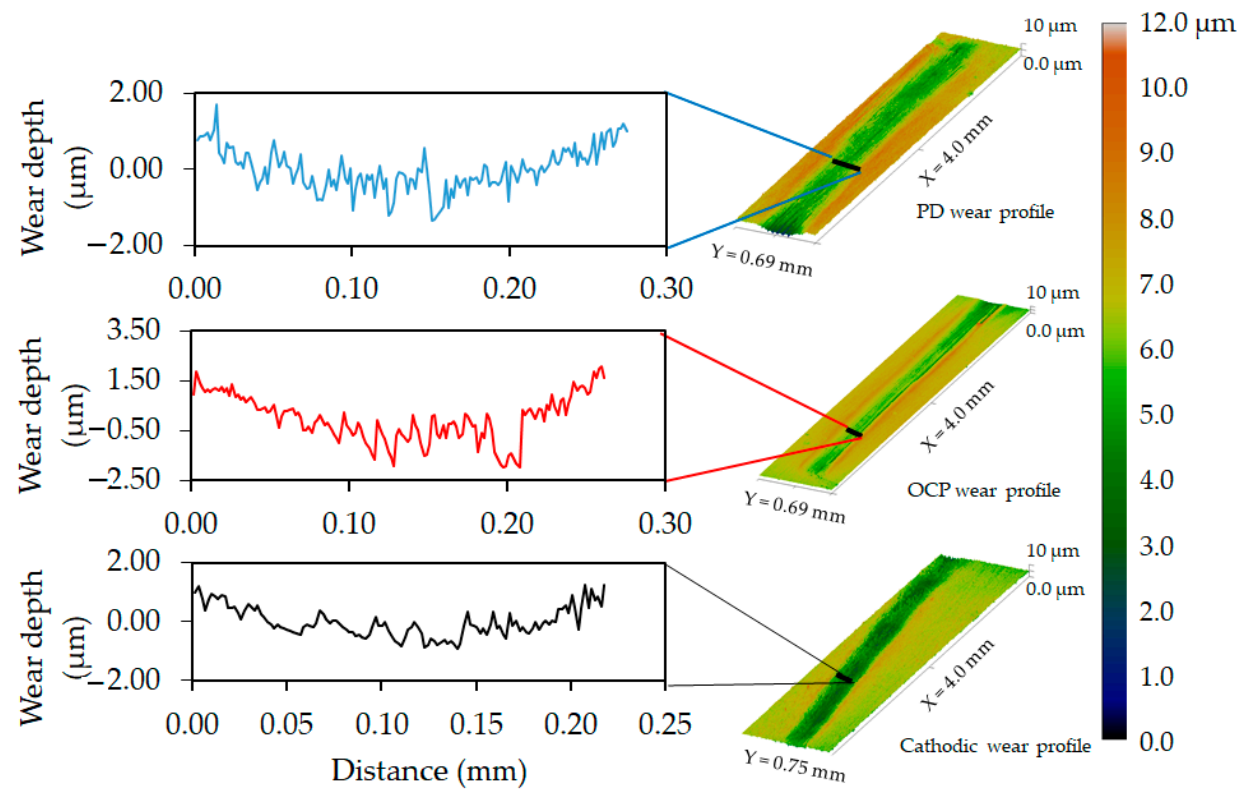

Figure 3. Wear on AM Inconel 718 after (a) potentiodynamic test, (b) OCP condition, and (c) cathodic polarization test shown alongside a common color scale bar.

Comparing the potentiodynamic and OCP wear volume results, it is observed that the wear is accelerated due to the onset of corrosion by a factor of $11.28 \%$ in the corrosive environment. It is believed that this is due to the small roughness reduction initially at the onset of corrosion, exposing the corrosion surface area and oxide film defect, increasing the susceptibility to corrosion product formation [22]. The corrosive environment itself seems to have a significant influence on surface degradation, as when the OCP and cathodic polarization wear volumes are compared, the wear seems to increase by $49.5 \%$. The synergistic effect considering the corrosion accelerated wear in the corrosive environment the wear volume increased by $55.25 \%$. This shows the drastic effect of aqueous corrosive environment on wrought Inconel 718.

In Figure 3, it can be observed that for AM Inconel 718, the potentiodyanamic wear volume is $1.22 \mathrm{~mm}^{3}$, the OCP wear volume is $1.71 \mathrm{~mm}^{3}$, and the cathodic polarization wear volume is $1.21 \mathrm{~mm}^{3}$. It is evident from comparing the OCP and cathodic polarization wear conditions that the corrosive environment increases the wear by $29.24 \%$ without the initiation of corrosion. It is interesting to note from the potentiodynamic polarization and OCP wear volumes that the initiation of corrosion actually decreases wear volume by $28.7 \%$. This indicates that the AM Inconel 718 has a directional solidification during its fabrication and can be equal to or exceed the mechanical properties of wrought counterpart, in this case it is observed as reduced wear volume. Studies have shown that the corrosion resistance of the AM Inconel 718 samples increases with the increasing incline angle of LPBF process, and this can be rationalized by considering changes to the grain boundary area [16]. The synergistic effect considering the corrosion accelerated wear is found be extremely low at only $\sim 1 \%$ increase in wear volume. It is expected that there is a small degree of electropolishing that occurs on the surface of the AM Inconel 718 in tribocorrosive environment, which can increase pitting corrosion resistance [23]. These results indicate that AM of Inconel 718 has a significant influence on the tribocorrosion performance as compared to the wrought counterpart. The corrosion results are further investigated in the following section.

\subsection{Corrosion Rate during Tribocorrosion}

The corrosion rate was calculated using the corrosion current $\left(I_{\text {corr }}\right)$ obtained during the tribocorrosion tests for wrought and AM Inconel 718. The corrosion rates were calculated for both with and without wear conditions as described in the tribocorrosion test 
methodology. The observed Tafel plot, along with their respective corrosion rates, is shown in Figure 4 . The shift in corrosion potential and corrosion current density due to the effect of corrosion and tribocorrosion can be clearly observed in this figure.

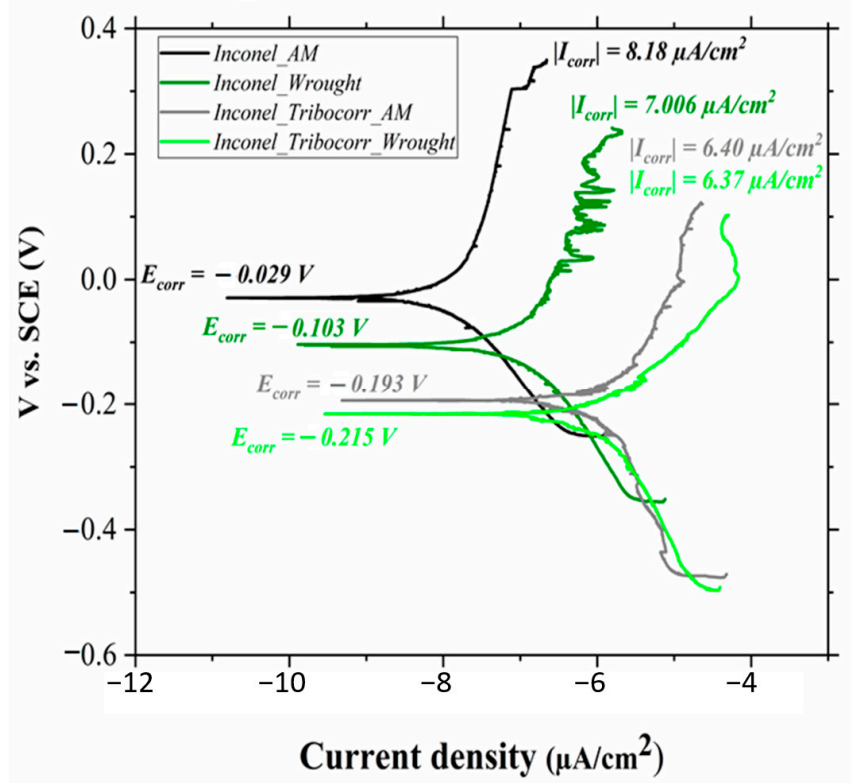

Without WEAR:

Corrosion rate Wrought

Inconel 718: $0.074 \mathrm{~mm} /$ year

Corrosion rate of $A M$

Inconel: $0.082 \mathrm{~mm} /$ year

With WEAR:

Corrosion rate Wrought

Inconel 718: $0.064 \mathrm{~mm} /$ year

Corrosion rate of $A M$

Inconel: $0.064 \mathrm{~mm} /$ year

Figure 4. Tafel plots and corrosion rate of wrought and AM Inconel 718 for various tribocorrosion test conditions.

It can be observed in Figure 4 that the corrosion potential $\left(E_{\text {corr }}\right)$ and corrosion current $\left(I_{\text {corr }}\right)$ under without wear condition for AM Inconel 718 is $-0.029 \mathrm{~V}$ and $8.18 \mu \mathrm{A} / \mathrm{cm}^{2}$ as compared to $-0.103 \mathrm{~V}$ and $7.006 \mu \mathrm{A} / \mathrm{cm}^{2}$ for wrought Inconel 718 , respectively. This indicates that the additively manufacturing Inconel 718 provides an enhanced corrosion resistance potential, which is the point of corrosion onset. This resistance potential for AM Inconel 718 is found to be $71.8 \%$ better than that for the wrought counterpart. Even though the corrosion rate of the under the same condition of without wear is found to be slightly more for AM Inconel 718 at $0.082 \mathrm{~mm} /$ year as compared to the wrought Inconel 718 at $0.074 \mathrm{~mm} /$ year, it can be expected that the onset of corrosion is delayed by $71.8 \%$ for AM Inconel 718. Hence, the observed reduction in wear under OCP conditions for AM Inconel 718 as compared to the wrought counterpart (Figures $2 \mathrm{~b}$ and $3 \mathrm{~b}$, respectively), where no corrosion potential was applied. Under the OCP wear condition, the Inconel 718 showed wear volumes of $1.71 \mathrm{~mm}^{3}$ and $2.28 \mathrm{~mm}^{3}$ for AM and wrought materials, respectively. The slightly lower corrosion current during the absence of wear for wrought Inconel 718 is found to be what provides it a $9.8 \%$ better corrosion resistance without wear but with an early onset of corrosion as compared to the AM Inconel 718.

Considering the wear with corrosion (tribocorrosion) it is observed that the $E_{c o r r}$ and $I_{\text {corr }}$ for both AM and wrought Inconel 718 shift to have an overall reduced corrosion rate, which confirms that the observed surface degradation is a corrosion accelerated wear. The wear volume is observed to increase in the same conditions (Figures 2a and 3a), but due to the delayed onset of corrosion, the wear in the case of AM Inconel 718 ( $1 \%$ increase) is minimal as compared to wrought Inconel 718 ( $55.25 \%$ increase). This unique behavior of Inconel 718 can be attributed to the anodic-to-cathodic transition potential (reverse portion of the potentidynamic scan) is more noble than corrosion potential. It can be believed, according to the Silverman's interpretation [24], that any film created on the reference Inconel 718 surface at the corrosion potential might not be very passivating and would allow uniform corrosion to occur at the corrosion potential. The above analysis can be summarized (in a similar way as in Davydov et al. [25]) by stating that using AM 
manufacturing significantly increases resistance to the pitting corrosion of Inconel 718, but does not increase its ability for passivation in $\mathrm{NaCl}$ solution.

\section{Conclusions}

The wear-corrosion synergism for the tribo-pair was be calculated using Equations (1) and (2). A positive synergy between wear and corrosion is highly undesirable. The experiment as detailed by ASTM G119 was used to analyze the tribocorrosion behavior of Inconel 718. The described method of tribocorrosion testing enables the measurement of the galvanic current between the passive (cathode, unworn area) and the depassivated (anode, worn area) areas of the sample surface at OCP. The following conclusions can be drawn from the present study:

(a) The corrosive environment increases the wear by $29.24 \%$ and $49.5 \%$ without the initiation of corrosion in the case of AM and wrought Inconel 718, respectively.

(b) The onset of corrosion in case of AM Inconel 718 is delayed by $71.8 \%$ as compared to the wrought counterpart.

(c) The late onset of corrosion degradation (high corrosion resistance potential) provides better tribocorrosion resistance in the case of AM Inconel 718.

(d) Both AM and wrought Inconel 718 have similar corrosion rates during tribocorrosion, but the wear volume in case of AM is much lower $\left(1.22 \mathrm{~mm}^{3}\right)$ as compared to wrought $\left(2.57 \mathrm{~mm}^{3}\right)$

(e) A corrosion-accelerated wear form of tribocorrosion is observed for Inconel 718 .

(f) The corrosive environment has a significant effect on wear even when the Inconel 718 surface is in equilibrium potential with the corrosive environment, and no corrosion potential scan is applied.

Author Contributions: Conceptualization: A.S., P.K., and P.L.M.; Methodology: A.S. and A.K.; Software, A.S. and A.K.; Validation: A.S. and A.K.; Formal analysis: A.S., A.K., P.K., M.M., and P.L.M.; Investigation, A.S., A.K., and P.L.M.; Resources: J.A., P.K., M.M., and P.L.M.; Data curation, A.S. and A.K.; Writing—original draft preparation, A.S.; Writing—review and editing: A.S., A.K., P.K., J.A., and P.L.M.; Visualization: A.S. and A.K.; Supervision: P.K., M.M., and P.L.M.; Project administration: P.K. and P.L.M. All authors have read and agreed to the published version of the manuscript.

Funding: This research received no external funding.

Institutional Review Board Statement: Not applicable.

Informed Consent Statement: Not applicable.

Data Availability Statement: Data available on request due to restrictions e.g., privacy or ethical. The data presented in this study are available on request from the corresponding author. The data are not publicly available due to propriority materials, equipment, and fabrication process being studied.

Acknowledgments: The authors appreciate the facility and financial support by startup funding from the Department of Mechanical Engineering, and the Department of Chemical and Materials Engineering at the University of Nevada, Reno.

Conflicts of Interest: The authors declare no conflict of interest.

\section{References}

1. Rahman, M.; Seah, W.K.H.; Teo, T.T. The machinability of inconel 718. J. Mater. Process. Technol. 1997, 63, 199-204. [CrossRef]

2. Xavior, M.A.; Patil, M.; Maiti, A.; Raj, M.; Lohia, N. Machinability studies on INCONEL 718. IOP Conference Series: Materials Science and Engineering. In Proceedings of the International Conference on Advances in Materials and Manufacturing Applications (IConAMMA-2016), Bangalore, India, 14-16 July 2016.

3. Iturbe, A.; Giraud, E.; Hormaetxe, E.; Garay, A.; Germain, G.; Ostolaza, K.; Arrazola, P.J. Mechanical characterization and modelling of Inconel 718 material behavior for machining process assessment. Mater. Sci. Eng. A 2017, 682, 441-453. [CrossRef]

4. Wang, X.; Gong, X.; Chou, K. Review on powder-bed laser additive manufacturing of Inconel 718 parts. Proc. Inst. Mech. Eng. Part B J. Eng. Manuf. 2016, 231, 1890-1903. [CrossRef]

5. Jia, Q.; Gu, D. Selective laser melting additive manufacturing of Inconel 718 superalloy parts: Densification, microstructure and properties. J. Alloys Compd. 2014, 585, 713-721. [CrossRef] 
6. Zhang, B.; Liao, H.; Coddet, C. Selective laser melting commercially pure Ti under vacuum. Vacuum 2013, 95, 25-29. [CrossRef]

7. Kumar, P.; Farah, J.; Akram, J.; Teng, C.; Ginn, J.; Misra, M. Influence of laser processing parameters on porosity in Inconel 718 during additive manufacturing. Int. J. Adv. Manuf. Technol. 2019, 103, 1497-1507. [CrossRef]

8. Morton, P.A.; Taylor, H.C.; Murr, L.E.; Delgado, O.G.; Terrazas, C.A.; Wicker, R.B. In situ selective laser gas nitriding for composite TiN/Ti-6Al-4V fabrication via laser powder bed fusion. J. Mater. Sci. Technol. 2020, 45, 98-107. [CrossRef]

9. Fox, P.; Pogson, S.; Sutcliffe, C.J.; Jones, E. Interface interactions between porous titanium/tantalum coatings, produced by Selective Laser Melting (SLM), on a cobalt-chromium alloy. Surf. Coat. Technol. 2008, 202, 5001-5007. [CrossRef]

10. Krakhmalev, P.; Yadroitsev, I. Microstructure and properties of intermetallic composite coatings fabricated by selective laser melting of Ti-SiC powder mixtures. Intermetallics 2014, 46, 147-155. [CrossRef]

11. Heiden, M.J.; Deibler, L.A.; Rodelas, J.M.; Koepke, J.R.; Tung, D.J.; Saiz, D.J.; Jared, B.H. Evolution of 316L stainless steel feedstock due to laser powder bed fusion process. Addit. Manuf. 2019, 25, 84-103. [CrossRef]

12. Barros, R.; Silva, F.J.G.; Gouveia, R.M.; Saboori, A.; Marchese, G.; Biamino, S.; Salmi, A.; Atzeni, E. Laser powder bed fusion of Inconel 718: Residual stress analysis before and after heat treatment. Metals 2019, 9, 1290. [CrossRef]

13. Luo, S.; Huang, W.; Yang, H.; Yang, J.; Wang, Z.; Zeng, X. Microstructural evolution and corrosion behaviors of Inconel 718 alloy produced by selective laser melting following different heat treatments. Addit. Manuf. 2019, 30, 100875. [CrossRef]

14. Zhang, B.; Xiu, M.; Tan, Y.T.; Wei, J.; Wang, P. Pitting corrosion of SLM Inconel 718 sample under surface and heat treatments. Appl. Surf. Sci. 2019, 490, 556-567. [CrossRef]

15. Zhang, L.N.; Ojo, O.A. Corrosion behavior of wire arc additive manufactured Inconel 718 superalloy. J. Alloys Compd. 2020, 829, 154455. [CrossRef]

16. Du, D.; Dong, A.; Shu, D.; Zhu, G.; Sun, B.; Li, X.; Lavernia, E. Influence of build orientation on microstructure, mechanical and corrosion behavior of Inconel 718 processed by selective laser melting. Mater. Sci. Eng. A 2019, 760, 469-480. [CrossRef]

17. ASTM B637-18. Standard Specification for Precipitation-Hardening and Cold Worked Nickel Alloy Bars, Forgings, and Forging Stock for Moderate or High Temperature Service; ASTM International: West Conshohocken, PA, USA, 2018.

18. ASTM B895-16(2020)e1. Standard Test Methods for Evaluating the Corrosion Resistance of Stainless Steel Powder Metallurgy (PM) Parts/Specimens by Immersion in a Sodium Chloride Solution; ASTM International: West Conshohocken, PA, USA, 2020.

19. Archard, J.F. Contact and Rubbing of Flat Surfaces. J. Appl. Phys. 1953, 24, 981-988. [CrossRef]

20. ASTM G119-09(2016). Standard Guide for Determining Synergism Between Wear and Corrosion; ASTM International: West Conshohocken, PA, USA, 2016.

21. Siddaiah, A.; Khan, A.Z.; Ramachandran, R.; Menezes, L.P. Performance Analysis of Retrofitted Tribo-Corrosion Test Rig for Monitoring In Situ Oil Conditions. Materials 2017, 10, 1145. [CrossRef] [PubMed]

22. Wang, J.; Xu, J.; Zhang, X.; Ren, X.; Song, X.; Chen, X. An investigation of surface corrosion behavior of Inconel 718 after robotic belt grinding. Materials 2018, 11, 2440. [CrossRef] [PubMed]

23. Guo, P.; Lin, X.; Li, J.; Zhang, Y.; Song, M.; Huang, W. Electrochemical behavior of Inconel 718 fabricated by laser solid forming on different sections. Corros. Sci. 2018, 132, 79-89. [CrossRef]

24. Silverman, D.C. Tutorial on Cyclic Potentiodynamic Polarization Technique. In Proceedings of the CORROSION/98 Research Topical Symposium; NACE: San Diego, CA, USA, 1998; p. 21.

25. Davydov, A.D.; Shaldaeva, V.S.; Malofeevaa, A.N.; Chernyshovab, O.V.; Volgina, V.M. Determination of corrosion rate of rhenium and its alloys. Chem. Eng. 2014, 41, 289-294. 